\title{
Xenogenous fertilization of goat ova in the rabbit oviduct
}

\author{
V. H. Rao, B. C. Sarmah and N. K. Bhattacharyya \\ Division of Physiology and Climatology, Indian Veterinary Research Institute, \\ Izatnagar-243 122 U.P., India
}

\begin{abstract}
Summary. Eggs from superovulated goats were surgically placed in the oviducts of pseudopregnant rabbits previously inseminated with goat semen. Out of 81 eggs, 30 $(37 \%)$ exhibited two pronuclei or two blastomeres when recovered $24-36 \mathrm{~h}$ later. Transplantation of these embryos into foster nanny goats resulted in the birth of kids.
\end{abstract}

\section{Introduction}

The oviducal environment of the pseudopregnant rabbit has been shown to support xenogenous fertilization of hamster and squirrel monkey (DeMayo, Mizoguchi \& Dukelow, 1980) and bovine and porcine (Hirst, DeMayo \& Dukelow, 1981) ova. The presence of two polar bodies, two pronuclei or cleavage was generally considered as evidence of fertilization. Transfer of xenogenously fertilized ova to homologous foster mothers was never attempted. In the present investigation we have studied the xenogenous fertilization of goat eggs and followed them upto the birth of kids by transplantation of the zygotes into other nanny goats.

\section{Materials and Methods}

Oestrus was synchronized in 12 donor and 9 recipient Black Bengal nanny goats by feeding melengestrol acetate (MGA; Upjohn, Kalamazoo, MI, U.S.A.), $1.15 \mathrm{~g} /$ animal/day, for 16 days. On Day 16 of MGA feeding the donor females were injected s.c. with 500 i.u. PMSG (Sigma, St Louis, MO, U.S.A.) to induce superovulation. Oestrus was checked during the next 6 days by testing with vasectomized bucks every 4 h (Rao \& Bhattacharyya, 1980). When oestrus was detected each donor goat was given an i.v. injection of 750 i.u. hCG (Sigma) to induce ovulation from all mature Graafian follicles. The eggs were collected by flushing the oviducts (Agrawal, Mongha \& Bhattacharyya, 1982) $24-36 \mathrm{~h}$ after the onset of oestrus. At this time approximately $20 \%$ of all the eggs collected were devoid of cumulus investments but no distinction was made.

Oestrous rabbit does were injected i.v. with 100 i.u. hCG/doe to induce ovulation and pseudopregnancy. Fresh goat semen, collected in an artificial vagina, was surgically placed in the uterine horns $(0.2 \mathrm{ml} /$ horn $) 14-16 \mathrm{~h}$ after the hCG injection. Concomitantly collected goat eggs in $0.2 \mathrm{ml}$ saline $(8.0 \mathrm{~g} \mathrm{NaCl} / 1)$ were surgically placed into the oviducts $(1-2 \mathrm{~cm}$ through the fimbriated end) 14 $\mathrm{h}$ after the rabbits were inseminated. The rabbit does were killed by cervical dislocation and xenogenously fertilized eggs were recovered $24-36 \mathrm{~h}$ later. All the recovered eggs were washed in 2-3 changes of saline which ensured removal of accessory spermatozoa. Eggs that had two pronuclei, as seen under a phase-contrast microscope, or two blastomeres were considered fertilized and were transferred into the oviducts $(1-2 \mathrm{~cm})$ of recipient nanny goats $60-72 \mathrm{~h}$ after onset of oestrus 
(Agrawal et al., 1982). Since the recipient goats had no chance to come into contact with males, failure to return to oestrus was treated as evidence of pregnancy.

\section{Results}

A total of 97 goat eggs were placed in the rabbit oviducts. Of 82 recovered ova, $30(37 \%)$ had two pronuclei (9) or two blastomeres (21). Most of these eggs had a very thin layer of mucin around them. The remaining eggs did not show evidence of fertilization and some were undergoing fragmentation. However, many of the eggs that failed to undergo fertilization also had a number of spermatozoa (3-4/egg) adhering to the zona pellucida.

All the 30 xenogenously fertilized eggs were transferred to 9 recipient goat females and 5 became pregnant (Table 1). One recipient which received 4 fertilized eggs gave birth to 3 male kids 157 days after transfer. Unfortunately the remaining 4 pregnant recipients either aborted or died due to accidental infection with Pasturella haemolytica during mid-pregnancy. The stage of pregnancy and sex of the fetuses was confirmed post mortem (Table 1).

Table 1. Survival of xenogenously fertilized goat eggs in foster mothers

\begin{tabular}{cccccc}
\hline \multirow{2}{*}{$\begin{array}{c}\text { Recipient } \\
\text { goat }\end{array}$} & $\begin{array}{c}\text { No. of eggs } \\
\text { transferred }\end{array}$ & $\begin{array}{c}\text { Whether } \\
\text { pregnant }\end{array}$ & $\begin{array}{c}\text { Lestation } \\
\text { (days) }\end{array}$ & Male & Female \\
\hline 1 & 4 & Yes & 64 & 1 & 3 \\
2 & 2 & Yes & 97 & 1 & 1 \\
3 & 2 & Yes & 120 & 1 & 1 \\
4 & 3 & No & - & - & - \\
5 & 3 & No & - & - & - \\
6 & 4 & No & - & - & - \\
7 & 4 & Yes & 120 & 1 & - \\
8 & 4 & No & - & - & - \\
9 & 4 & Yes & 157 & 3 & - \\
\hline
\end{tabular}

\section{Discussion}

Xenogenous fertilization can be a very useful alternative to in-vitro fertilization, particularly for eggs from farm animals for which results of in-vitro fertilization have been disappointing (Wright \& Bondioli, 1981), although birth of a bull calf after in-vitro fertilization has been reported (Brackett et al., 1982). The birth of 3 live kids in this investigation provides unequivocal evidence of fertilization of goat eggs in the rabbit oviduct. The success in our study is higher than that reported for cows and pigs for which follicular oocytes were used and spermatozoa were simultaneously placed in the rabbit oviducts (Hirst et al., 1981). The transfer of goat eggs into the rabbit oviduct 14 $\mathrm{h}$ after deposition of goat spermatozoa probably provided the opportunity for capacitation of the goat spermatozoa in the rabbit reproductive tract and hence improved the chances of subsequent fertilization. Although goats might be more suitable than cows and sows for xenogenous fertilization, we believe that our time scale for collection and transfer of homologous mature gametes into the rabbit oviduct was primarily responsible for our success.

We thank the Director for providing the facilities. V.H.R. received financial support from the Council of Scientific and Industrial Research of India. 


\section{References}

Agrawal, K.P., Mongha, I.V. \& Bhattacharyya, N.K. (1982) Collection and transfer of embryos in goats : surgical method. Ind. vet. J. 59, 298-303.

Brackett, B.G., Bousquet, D., Boice, M.L., Donawick, W.J., Evans, J.F. \& Dressel, M.A. (1982) Normal development following in-vitro fertilization in the cow. Biol. Reprod. 27, 147-158.

DeMayo, F.J., Mizoguchi, H. \& Dukelow, W.R. (1980) Fertilization of squirrel monkey and hamster ova in the rabbit oviduct (xenogenous fertilization). Science, N.Y. 208, 1468-1469.
Hirst, P.J., DeMayo, F.J. \& Dukelow, W.R. (1981) Xenogenous fertilization of laboratory and domestic animals in the oviduct of the pseudopregnant rabbit. Theriogenology 15, 67-75.

Rao, V.H. \& Bhattacharyya, N.K. (1980) Ovulation in Black Bengal nanny goats. J. Reprod. Fert. 58, 67-69.

Wright, W.R. \& Bondioli, K.R. (1981) Aspects of in vitro fertilization and embryo culture in domestic animals. J. Anim. Sci. 53, 702-709.

Received 24 August 1983 